samples were tested by both solid phase assays. None of the 25 serum samples tested was positive for the anti-29 kilodalton ELISA. Four out of 27 serum samples were positive for the anti-myeloperoxidase ELISA and negative for antinuclear antibody testing. Anti-myeloperoxidase positive serum samples were P-ANCA positive $(n=3)$ or immunofluorescence negative $(n=1)$. No marked hypergammaglobulinaemia could explain 'false' positive results by non-specific Fc receptor binding. No association was found between the presence of ANCA and either vasculitis or glomerulonephritis. The serum of one patient with relapsing polychondritis-Wegener's granulomatosis overlap contained P-ANCA at a titre of $1 / 20$. Among the eight patients positive for ANCA, relapsing polychondritis was active in seven, whereas it was active in only 12 out of 25 ANCA negative patients $(p=0 \cdot 1$, two tailed Fisher's test)

These results suggest that low titres of C-ANCA are not specific for Wegener's granulomatosis and that ANCA (either diffuse or perinuclear) may be present in $24 \%$ of serum samples from patients with relapsing polychondritis, especially during the active phase of the disease.

T PAPO J C PIETTE HUONG DU P GODEAU Service de Médecine Interne Groupe Hospitalier Pitié-Salpêtrière 75651 Paris Cedex 13, France

$$
\begin{array}{r}
\text { O MEYER } \\
\text { MF KAHN } \\
\text { Hhumatologie } \\
\text { Hopital Bichat } \\
75018 \text { Paris, France }
\end{array}
$$

P BOURGEOIS Service de Rhumatologie Groupe Hospitalier Pitié-Salpêtrière 75651 Paris Cedex 13, France

Correspondence to: $\mathrm{Dr}$ Thomas Papo, Service de Médecine Interne, Groupe Hospitalier PitiéSalpêtrière, 83 bd de l'Hôpital, 75651 Paris Cedex 13, France.

1 Ludeman J, Utecht B, Gross W. Anti-neutrophil cytoplasm antibodies in Wegener's granulomatosis recognize an elastinolytic enzyme. f Exp Med 1990; 171: 357-62.

2 Hagen E C, Ballieux B E, Daha M R, van Hes L A, van der Woude F J. Fundamental and clinical aspects of antineutrophil cytoplasmic clinical aspects of antineutrophil cytoplasmic

3 Specks U, Wheatley C L, McDonald T J, Rohrbach M S, Deremee R A. Anticytoplasmic autoantibodies in the diagnosis and follow-up of Wegener's granulomatosis. Mayo Clin Proc 1989; 64: 28-36.

4 Michet C J, McKenna C H, Luthra H S, O'Fallon W M. Relapsing polychondritis. Ann Intern Med 1986; 104: 74-8.

5 Wiik A. Delineation of a standard procedure for indirect immunofluorescence detection of ANCA. Acta Pathol Microbiol Immunol Scand 1989; 97: 12-13.

\section{Two sisters with ANCA positive vasculitis}

Antineutrophil cytoplasmic antibodies (ANCAs) have been shown to be associated strongly with microscopic polyarteritis nodosa and Wegener's granulomatosis. ${ }^{12}$ These antibodies have also been found in patients with other vasculitic disorders, including Kawasaki disease, Churg-Strauss syndrome, and relapsing polychondritis. ${ }^{34}$ Factors governing production of ANCA remain unknown, though infection has been implicated as a possible trigger for onset of relapse of Wegener's granulomatosis. ${ }^{56} \mathrm{We}$ describe two sisters with ANCA positive vasculitic diseases.

The first patient, aged 55 years, presented with arthralgia and subsequently developed uveitis and scleritis, swelling of the nasal cartilage, chondritis of her ear, and costochondritis. She had an episode of transient diplopia and a Bell's palsy. A diagnosis of relapsing polychondritis was made. She was initially treated with steroids and a non-steroidal anti-inflammatory drug but subsequently required azathioprine to control her symptoms. She remains well six years later, having had two minor relapses in the interim. There has been no evidence of renal disease.

The second sister presented at the age of 54 years with nasal stuffiness, impaired hearing, episcleritis, myalgia, abnormal liver function, and proteinuria. A diagnosis of Wegener's granulomatosis was made. She has responded well to cyclophosphamide and remains in remission 18 months later.

Investigations have shown that both sisters have been repeatedly positive for ANCA. Patient 1 had a perinuclear pattern of staining (pANCA) with a maximum titre of $1 / 64$ (on treatment), whereas patient 2 had a cytoplasmic pattern of staining (cANCA) with a maximum titre of $1 / 512$. The sisters are HLA identical-A2, A10, B27, Bw4, Cw1, DR8, DR9.

As far as we know, this is the first report of ANCA positive vasculitis in siblings. There is a striking similarity between the age of onset and the clinical features of the two cases despite the different diagnoses. They are HLA identical. These cases suggest a role for genetic factors in the development of ANCA positive vasculitis, which merits further study. They also highlight the fact that within the spectrum of vasculitis there is considerable overlap in the clinical features of patients with different vasculitic disorders.

It is now recognised that the immunofluorescent staining patterns obtained when testing for ANCA reflect different antibody specificities - CANCA being associated with antibodies to proteinase- 3 and pANCA being associated with antibodies to myeloperoxidase in some cases. It is therefore of interest that our two cases had different staining patterns.

There have been two recent reports of an HLA association in patients with ANCA positive vasculitis. Spencer et al found an association between HLA-DQw7 and susceptibility to ANCA related disease, while possession of HLA-DR5 or DR6 seemed to prolong the duration of ANCA synthesis.? Papiha et al reported an association between Wegener's granulomatosis and HLA-DR1. It is therefore of interest that these two sisters are HLA identical, though they do not possess any of the HLA antigens previously associated with ANCA positive vasculitis.

E A MURPHY R D STURROCK Centre for Rheumatic Diseases University Department of Medicine Glasgow Royal Infirmary Glasgow G31 2ER United Kingdom J G FOX J M BOULTON-JONES University Department Renal Unit Glasgow Royal Infirmary Glasgow G31 2ER

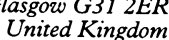

1 Van der Woude F J, Rasmussen N, Lobatto S, et al. Autoantibodies against neutrophils and monocytes: tool for diagnosis and marker of disease activity in Wegener's granulomatosis. Lancet 1985; i: 425-9.

2 Lockwood C M, Bakes D, Jones S, Whitaker K B, Moss D W, Savage C O S. Association of alkaline phosphatase with an autoantigen recognised by circulating an autoantigen recognised by circulating anti-neutrophil i: $716-9$.

3 Venning M C, Arfeen S, Bird A G. Antibodies to neutrophil cytoplasmic antigen in systemic vasculitis. Lancet 1987; ii: 850 .

4 Savage C O S, Lockwood C M. Autoantibodies in primary systemic vasculitis. Ann Intern $\mathrm{Med}$ 1990; 35: 73-92.

5 Pinching A J, Rees A J, Pussell B A, et al. Relapses in Wegener's granulomatosis: the role of infection. BMF 1980; 281: 836.

6 Csernok E, Schmitt W H, Ernst M, Bainton D, Gross W L. Translocation of proteinase-3 on the cell membrane of polymorphonuclear the cell membrane of polymorphonuclear leucocytes in Wegener's granulomatosis:
correlation with disease activity. Clin correlation with disease
Rheumatol 1992;11: 124 .

7 Spencer S J, Burns A, Gaskin G, Pusey C, Rees A J. Influence of HLA class II genes on susceptibility to vasculitis. Nephrol Dial Transplantation 1991; 6: 900 .

8 Papiha S S, Murty G E, Ad'Hia A, Mains B T, Venning $M$. Association of Wegener's granulomatosis with HLA antigens and other genetic markers. Ann Rheum Dis 1992; 51: genetic

\section{Acquired Brown's syndrome in a patient with SLE}

Sir: We read with interest the recent article by Alonso-Valdivielso et $a l^{1}$ describing a patien with systemic lupus erythematosus (SLE) who later developed Brown's syndrome. In view of the authors' statement that this association has not previously been described we wish to draw your attention to two previously published reports.

In 1990 we published a case report ${ }^{2}$ in which the patient, a 30 year old man, initially sought medical advice as a result of his ocular symptoms of variable double vision on upgaze. Only the left eye was affected and on examination restricted elevation of the adducted left eye produced diplopia associated with pain and a palpable click over the trochlea. A diagnosis of left Brown's syndrome was made following Hess chart assessment. The condition settled during treatment with ibuprofen $1200 \mathrm{mg}$ daily. A five month history of arthralgia affecting the hands, wrists, elbows, shoulders, hips, and knees and acute alopecia one year before was noted. Later examination during febrile flare disclosed rash, lymphadenopathy, and synovitis of the hands, left elbow, shoulders, and knees. Investigations, including antinuclear antibody, dsDNA antibody, complement and immune complex levels, confirmed SLE.

In our discussion we made reference to an earlier review of Brown's syndrome which included a description of the condition occurring in a patient with established SLE. We agree with Alonso-Valdivielso et al that Brown's syndrome should be considered in patients with diplopia and SLE. We consider that the true incidence of clinical disease may well be higher than these three reports suggest, perhaps because of mild or transient symptomatology and difficulty in diagnosis without orthoptic assistance.

JAMES MCGALLIARD Royal Liverpool University Hospital
Liverpool 7 Liverpool 7
United Kingdom 